\title{
Disturbances of Sleep Among Older People and Its Influence on Cognitive Performance
}

\author{
Alicja Różyk-Myrta1 ${ }^{1}$ Andrzej Brodziak ${ }^{1,2 *}$ Estera Kołat ${ }^{1}$, Anna Komarow-Kuźmińska ${ }^{1}$ and Barbara Białkowska \\ 1 Institute of Nursing, University of Applied Sciences, Armii Krajowej St. 7, 48-300 Nysa, Poland
}

${ }^{2}$ Institute of Occupational Medicine and Environmental Health, Koscielna St. 13, 41-200, Sosnowiec, Poland

\begin{abstract}
Sleep disorders are common in the general population. People suffering from a variety of general, neurological, and mental disorders are in high risk group. Insomnia, which is the most often form of sleep disorder, can be the onset of depression. Symptoms accompanying various neurological disorders are often a consequence of underlying sleep disorders.
\end{abstract}

Objective: Examining the correlation between sleep disorders and the reduction of cognitive abilities among older people.

Methods: We gathered data from 56 respondents from the University of the Third Age, aged between 52 and 81. We also performed certain objective measurements, using Montreal Cognitive Assessment (MOCA), a test of working memory system and the measurements of "visuomotor" coordination.

Results: Correlation has been found between the results from the proposed sleep quality scale and the outcome of MOCA as well as other measurements.

Conclusion: The link between sleep disorders and cognitive abilities in older individuals is most probably significant.

Keywords: Sleep disorders; Older; Cognitive; Quality

\section{Introduction}

Researchers interested in the causes of premature cognitive impairment and dementia emphasize the importance of risk factors predisposing to these clinical conditions. Some of these researchers attach greater importance to the somatic risk factors. Other researchers attribute a greater role to lifestyle, stressful events and acquired competencies counteracting negative influences.

Deckers et al. on the basis of their study enumerate the following as the most important risk factors for dementia: depression, hypertension, diabetes, obesity, hyperlipidemia, physical inactivity, and smoking [1].

Kremen et al. are convinced that the early emergence of cognitive impairments results rather from the quality of mother-infant interactions, adverse events in childhood, long cumulative exposure to stress, ineffective coping strategies, sustained negative emotions, unhappiness, rumination, and many social factors (eg., social ties, network size, integration, support, and conflicts) [2].

The study found a higher level of conjugal happiness among women with calmer sleep. It is difficult to say whether happy people sleep better. Better sleep makes people feel happier. Insomnia doubles the chance of developing depression [3].

According to Kremen et al. neuroticism, negative affectivity, depression or emotional instability in old age are a good indicator of the cumulative level of psychological stress experienced during the life span. So, according to them-the stress-related variables are important predictors of cognitive aging.

Sleep is indispensable to a correct course of psychological processes. Even a single sleepless night may decrease mental and physical fitness. Sleep is a functional status of the central nervous system appearing regularly in circadian rhythm, during which consciousness and activity are inhibited. Physiological sleep is characterized by full reversibility under the influence of external factors (contrary to a coma) [4].

Short sleep is particularly impairing to the functioning of the brain and can contribute to problems with memorization and concentration.
It is also characterized by a higher risk of false memories and obesity [5-7]. Sleep deprivation impairs constructive thinking abilities and facilitates making risky decisions [8-9].

Sleep is necessary for maintenance of homeostasis of the whole body [10]. It has a significant influence on the nervous, immune, endocrine, and cardiovascular systems $[11,12]$. It plays a vital role in the proper functioning of the body, enabling recovery, improvement in concentration and memorization abilities, optimization of responses to stress and enhancement of immune system. Moreover, the anabolic hormones secreted during sleep stimulate restoration of tissues. Sleeplessness in younger individuals results in feeling unwell or tired, decreased motivation, concentration and memorization as well as reduction in productivity and increased risk of an accident [13-16].

Sleep disorders are common in the whole of society. Some groups are more vulnerable. These are the elderly, women and patients with general, mental and neurological conditions.

All over the world, the proportion of elderly people is rapidly increasing. Geriatrics and other medical staff are more and more often having to cope with the treatment of conditions that increase with age. An example of such a condition is sleep apnea. In older patients, sleep fragmentation is intensified (intermittent sleep, multiple or partial wake). The share of stages 3 and 4 is decreasing [17]. These changes may be related.

Sleep disturbances in the elderly can lead to structural changes

*Corresponding author: Andrzej Brodziak, Institute of Occupational Medicine and Environmental Health, Koscielna St. 13, 41-200, Sosnowiec, Poland, Tel: + 48605044605, Email: andrzejbrodziak@wp.pl

Received April 23, 2017; Accepted August 08, 2017; Published August 12, 2017

Citation: Różyk-Myrta A, Brodziak A, Kołat E, Komarow-Kuźmińska A, Białkowska B (2017) Disturbances of Sleep Among Older People and Its Influence on Cognitive Performance. J Gerontol Geriatr Res 6: 443. doi:10.4172/2167-7182.1000443

Copyright: @ 2017 Różyk-Myrta A, et al. This is an open-access article distributed under the terms of the Creative Commons Attribution License, which permits unrestricted use, distribution, and reproduction in any medium, provided the original author and source are credited. 


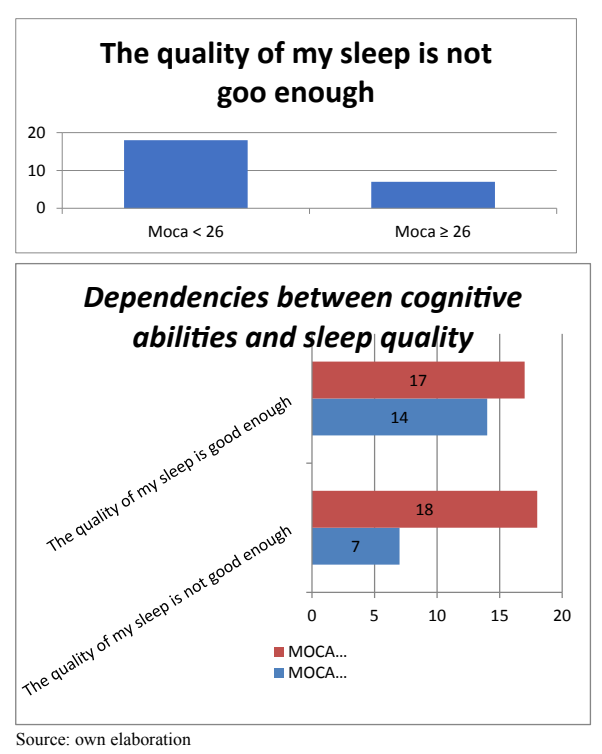

Figure 1: Dependencies between cognitive abilities and sleep quality.

\begin{tabular}{|c|c|}
\hline Sr No. & Some symptoms \\
\hline 1 & The quality of my sleep is not good enough \\
\hline 2 & Trouble with sight \\
\hline 3 & Impaired hearing \\
\hline 4 & Trouble with memory \\
\hline 5 & Trouble with orientation in time and space \\
\hline 6 & Feeling helpless, exhausted, \\
\hline 7 & Feeling of lack of hope, \\
\hline 8 & I think I'm depressed \\
\hline
\end{tabular}

Source: Own elaboration

Table 1: A review of the somatic state, treatment, nutrition, and genetic conditioning.

in the brain that are associated with long-term memory disorders. In adults, memory deficits associated with lack of sleep are also observed. Already in 1924, it was discovered that people who sleep longer remember more. Poor sleep and deficiency is associated with a higher level of substance that causes Alzheimer's disease [18] (Figure 1).

In older individuals, functional efficiency regarding complex everyday activities decreases, while the risk of falling increases. It has been proven, that a link exists between sleep and cognitive abilities in older individuals [19].

Chronic sleep deprivation leads to decrease in immunity and a greater susceptibility to infections. In older individuals, the above disorders also contribute to an increased risk of death [20,21].

In older individuals, sleep disorders are a result of a contribution of multiple factors [22]. These include changes in circadian rhythm, medical conditions (insomnia often concurs with cardiovascular or mental illnesses, e.g., depression or anxiety disorders), medications as well as psychosocial changes connected with aging, such as retiring, limited fitness and lowered physical activity or lack of motivation and need to enter into contact with somebody [23-25].

\section{The Material and Method of the Preliminary Trial}

The survey was carried out from 27 March to 20 May 2015 among the participants of the so-called University of Third Age. The study was conducted in two stages. In the first stage, the participants were surveyed according to the items of the structured interview. The fragment of this interview related to the somatic state, treatment, nutrition, and genetic conditioning (a short own, proposed scale) is presented in Table 1. The form of the interview encompassed the note of the reaction to the statement formulated as: "The quality of my sleep is not good enough" [26].

In the second stage, we performed some objective measurements. We used the so-called Montreal Cognitive Assessment (MOCA). All necessary information for the application of this neuro-psychological test are available on the MOCA website. The first stage of the survey was completed by 90 people between 52 years and 81 years of age. Whole program of the study (I and II stage) was completed by 56 people.

Among others, we attempted to compare the dependence between sleep disorders and cognitive abilities.

\section{Results}

The mean value of the result of MOCA test was 24.37 (standard deviation 2.96). Almost half of the respondents $\mathrm{N}=25$ (45\%) described their sleep quality as not good enough. The majority $\mathrm{N}=18(72 \%)$ of older individuals describing their sleep quality as not good enough scored below 26 points in MOCA, which indicated reduced cognitive abilities. This outcome illustrates a dependency between sleep quality and cognitive disorders.

\section{Discussion}

At present, many researchers emphasize the influence of sleep quality on somatic diseases and efficient functioning of the brain. The evolutionary role of sleep is not fully defined. It is claimed that the most important function of sleep is to ensure efficiency during standby [27]. It guarantees, among others, physical recovery as well as facilitates creating memories and learning process. In the event of sleep disorders, which are often experienced by older people $\mathrm{N}=25$ ( $45 \%$ of the surveyed group of older people), they should not be underestimated, as sleep deprivation significantly reduces the functioning of the body and wellbeing. The conducted research confirms the influence of sleep disorders on older people's cognitive abilities.

\section{Conclusion}

1. Sleep disorders are common in the general population, but some groups are more vulnerable to it. These people include the elderly.

2. The study confirms the connection between sleep quality and cognitive abilities.

3. Sleep disorders are common in patients with dementia. They can cause excessive drowsiness, irritability, deterioration of cognitive ability, depression, and fatigue. It can be assumed that in sleep disorders there is a so-called "vicious circle" where sleep disorders can be predictors of progressive dementia.

4. Searching for risk factors for cognitive disorders is the direction of research that we continue. This may help to identify these diseases more quickly and prevent them.

\section{References}

1. Deckers K, Schiepers OJ, Anstey KJ, Brayne C, Dartigues JF, et al. (2015) Target risk factors for dementia prevention: A systematic review and Delphi consensus study on the evidence from observational studies. Int J Geriatr Psychiatry 30: 234-246.

2. Kremen WS, Lachman ME, Pruessner JC, Sliwinski M, Wilson RS (2012) Mechanisms of age-related cognitive change and targets for intervention: Social interactions and stress. J Gerontol Biol Sci Med Sci 67: 760-765.

3. Baglioni C, Battagliese G, Feige B, Spiegelhalder K, Nissen C, et al. (2011) Insomnia as a predictor of depression: A meta-analytic evaluation of longitudinal epidemiological studies. J Affect Disord 135: 10-19. 
Citation: Różyk-Myrta A, Brodziak A, Kołat E, Komarow-Kuźmińska A, Białkowska B (2017) Disturbances of Sleep Among Older People and Its Influence on Cognitive Performance. J Gerontol Geriatr Res 6: 443. doi:10.4172/2167-7182.1000443

4. PWN (2007) Polish dictionary, collective work, Scientific publishing house.

5. Rybakowski J, Pużyński S, Wciórka J (2010) Psychiatry. Fundamentals of psychiatry.

6. Abel T, Havekes R, Saletin JM, Walker MP (2013) Sleep, plasticity and memory from molecules to whole-brain networks. Curr Biol 23: R774-R788.

7. Frenda SJ, Patihis L, Loftus EF, Lewis HC, Fenn KM (2014) Sleep deprivation and false memories. Psychol Sci 25: 1674-1681.

8. Taheri S (2006) The link between short sleep duration and obesity: We should recommend more sleep to prevent obesity. Arch Dis Child 91: 881-884.

9. Killgore WD, Kahn-Greene ET, Lipizzi EL, Newman RA, Kamimori GH, et al. (2008) Sleep deprivation reduces perceived emotional intelligence and constructive thinking skills. Sleep Med 9: 517-526.

10. Bezsenność SM (2014) Pathogenesis and treatment. Probl Sci Biol 63: 233243

11. Wojtas A, Ciszewski S (2011) Epidemiology of insomnia. Psychiatry 8: 79-83.

12. Passos GS, Poyares DL, Santana MG, Tufik S, Mellol MT (2012) Is exercise an alternative treatment for chronic insomnia? Clinics 67: 653-659.

13. McCall WV (2004) Sleep in the elderly: Burden, diagnosis, and treatment. Prim Care Companion. J Clin Psychiatry 6: 9-20.

14. Li Y, Zhang X, Winkelman JW, Redline S, Hu FB, et al. (2013) Association between insomnia symptoms and mortality. A prospective study of US Men. Circulation 129: 737-746.

15. Ancoli-Israel S, Cooke JR (2005) Prevalence and comorbidity of insomnia and effect on functioning in elderly populations. J Am Geriatr Soc 53: S264-S271.

16. Cooke JR, Ancoli-Israel S (2006) Sleep and its disorders in older adults. Psychiatr Clin North Am 29: 1077-1093.
17. Avidan AY (2002) Sleep changes and disorders in the elderly patient. Curr Neurol Neurosci Rep 2: 178-185.

18. Spira AP, Gamaldo AA, An Y, Wu MN, Simonsick EM, et al. (2013) Selfreported sleep and $\beta$-amyloid deposition in community-dwelling older adults. JAMA Neurol 70: 1537-1543.

19. Yaffe K, Falvey CM, Hoang $T$ (2014) Connections between sleep and cognition in older adults. Lancet Neurol 13: 1017-1028.

20. Kamel NS, Gammack JK (2006) Insomnia in the elderly: Cause, approach, and treatment. Am J Med 119: 463-469.

21. Krishnan $P$, Hawranik $P$ (2008) Diagnosis and management of geriatric insomnia: A guide for nurse practitioners. J Am Acad Nurse Pract, 20: 590-599.

22. Jaussent I, Ancelin ML, Berr C, Pérès K, Scali J, et al. (2013) Hypnotics and mortality in an elderly general population: A 12-year prospective study. BMC Medicine 11: 212.

23. Wennberg AM, Canham SL, Smith MT, Spira AP (2013) Optimizing sleep in older adults: Treating insomnia. Maturitas 76: 247-252.

24. Brodziak A, Kołat E, Różyk-Myrta A, Kuźmińska A, Wolińska A, et al.(2015) A structured interview for evaluation of medical and mental risk factors predisposing to early cognitive impairment and dementia. Med Sci Tech 56: $127-144$.

25. Nasreddine ZS, Phillips NA, Bédirian V, Charbonneau S, Whitehead V, et al (2005) The Montreal cognitive assessment, MoCA: A brief screening tool for mild cognitive impairment. J Am Geriatr Soc 53: 695-699.

26. Montreal cognitive assessment screenig tool (2016), Montreal, Canada.

27. Siegel JM, Rogawski MA (1988) A function for REM sleep: Regulation of noradrenergic receptor sensitivity. Brain Res Rev 472: 213-233. 